\title{
Catherine Lanoë, La poudre et le fard, une histoire des cosmétiques de la Renaissance aux Lumières
} Seyssel, Champ Vallon, 2008.

\section{Georges Vigarello}

\section{(2) OpenEdition \\ Journals}

Édition électronique

URL : http://journals.openedition.org/dht/593

DOI : $10.4000 /$ dht.593

ISSN : $1775-4194$

Éditeur :

Centre d'histoire des techniques et de l'environnement du Cnam (CDHTE-Cnam), Société des élèves du CDHTE-Cnam

\section{Édition imprimée}

Date de publication : 31 mars 2009

Pagination : 235-236

ISBN : 978-2-95-30779-3-3

ISSN : 0417-8726

Référence électronique

Georges Vigarello, « Catherine Lanoë, La poudre et le fard, une histoire des cosmétiques de la

Renaissance aux Lumières », Documents pour l'histoire des techniques [En ligne], 17 | 7 er semestre 2009, mis en ligne le 27 septembre 2010, consulté le 21 septembre 2020. URL : http://

journals.openedition.org/dht/593; DOI : https://doi.org/10.4000/dht.593

Ce document a été généré automatiquement le 21 septembre 2020.

(C) Tous droits réservés 


\section{Catherine Lanoë, La poudre et le fard, une histoire des cosmétiques de la Renaissance aux Lumières}

Seyssel, Champ Vallon, 2008.

\section{Georges Vigarello}

\section{RÉFÉRENCE}

Catherine Lanoë, La poudre et le fard, une histoire des cosmétiques de la Renaissance aux Lumières, Seyssel, Champ Vallon, 2008.

1 Catherine Lanoë a su conduire une enquête minutieuse sur un objet souvent ignoré des historiens : le recours aux cosmétiques durant la période moderne. Elle l'a fait selon une démarche pluridisciplinaire où se mêlent, avec une constante pertinence, les interrogations sur la chimie des objets, leur circulation et leur marché, leurs enjeux esthétiques, leurs significations culturelles ou sociales, leurs valeurs de distinction. Des pratiques, longtemps jugées superficielles ou dérisoires, prennent alors une profondeur insoupçonnée, éclairant les sociabilités, les modes de domination, les circulations des modèles entre les groupes sociaux, la très lente conscience du risque sanitaire venue des produits aussi, et dès lors, les tentatives "savantes" de vérification ou de correction. L'enquête, la première du genre, la première surtout à embrasser une telle diversité de champs, se révèle tout simplement remarquable.

2 L'attention aux mots d'abord est importante qui, au-delà de leur versant technique, suggère aussi leur versant moral : le rejet durable du mot « fard " par exemple, dans le monde moderne, terme connotant l'artifice, la tromperie, frappé dès lors d'anathème, même si une pratique assez largement répandue consiste à recourir au produit « masquant ». Le vocable est le plus souvent remplacé par celui de «blanc» ou par les expressions de "blanc de Candie», "blanc de perles» ou "blanc d'Espagne». La 
crainte du «mensonge » sur l'apparence s'avère forte, même si blanchir demeure le geste central.

3 C'est aussi que le blanc a une valeur précise. Il est censé magnifier une pureté physique autant qu'une pureté morale: la perfection des humeurs, la perfection du comportement. Le blanc ramasse les valeurs de distinction, loin des stigmates laissés par les labeurs, loin des rougeurs ou du hâle laissés par les intempéries. Le «brillant » l'emporte d'ailleurs dans les critères valorisés, transposant le produit en témoin d'une beauté lumineuse diffusant éclat et rayons. Ce qui fait la différence des prix: les hiérarchies observées par les textes de recettes et de « secrets » entre la cire « fine » et la cire « commune ", la " pouldre subtile » et la " pouldre de riz », la « litharge d'or » et la « litharge de plomb». Ce qui fait aussi la différence des dangers : les produits les plus " argentés ", les plus immédiatement visibles et précieux, étant les plus nocifs, ceux mêlés de minéraux, mercure, plomb ou bismuth. La coloration encore s'enrichit avec le monde classique : le rouge venant, le plus subtilement, se mêler au blanc pour ajouter une discrète teinte de sang à ce qui revendique l'immaculé.

L'exploration du marché, l'étude minutieuse des archives commerciales, le relevé attentif des fabrications et des coûts, font un autre intérêt du livre. Catherine Lanoë montre d'abord l'origine des modèles, le rôle majeur joué par la cour, la très lente diffusion à la ville. Elle montre aussi le passage d'une pratique domestique, celle des cuisines et des offices, à une pratique de marchands, celle des parfumeurs, des épiciers, des colporteurs, l'élaboration de clientèles lentement fidélisées: signe d'une incontournable légitimation de l'artifice. Elle montre surtout comment s'installe, au sein même de la cour, un ensemble d'intermédiaires censés acheter pour leurs maîtres avant d'acheter pour eux-mêmes, vendre pour leur propre compte et diffuser dans les groupes « inférieurs » les modèles des grands. La domesticité est ici déterminante à la fin de l'Ancien Régime, comme l'a montré Daniel Roche pour le vêtement, diffusant les codes autant que les consommations.

Reste l'aiguisement d'une conscience des dangers. Non que se soit nécessairement approfondie l'analyse chimique. La mesure du risque en revanche s'est totalement transformée avec la société des Lumières: celui venu du mercure ou du plomb en particulier. Les "inventeurs" de cosmétiques s'adressent plus fréquemment à l' Académie des sciences après 1770 . Le roi crée d'ailleurs la Société royale de médecine en 1778 pour régenter toute autorisation sur les «remèdes secrets ». D'où le triomphe avec la fin du siècle des matières végétales, jugées "moins dangereuses»: ces "Toilettes de Flore » où le rouge s'obtient davantage avec du safran, le "carthame " issu de la fleur, qu'avec le vermillon issu du bismuth. D'où aussi ces teintes plus douces jouant avec le naturel et la physionomie. Catherine Lanoë montre au passage que c'est tout simplement la vie de la peau, sa spécificité, qui s'inventent avec ces risques mieux mesurés. Ultime exemple, s'il le fallait, confirmant combien l'approche de ce livre sait faire du cosmétique un fait social total. 


\section{AUTEURS}

GEORGES VIGARELLO

EHESS 